\title{
3D COMPARISON TOWARDS A COMPREHENSIVE ANALYSIS OF A BUILDING IN CULTURAL HERITAGE
}

\author{
Ilenia Selvaggi ${ }^{1}$, Mirko Dellapasqua ${ }^{1}$, Francesca Franci ${ }^{1}$, \\ Anna Spangher ${ }^{2}$, Domenico Visintini ${ }^{2}$, Gabriele Bitelli ${ }^{1}$ \\ ${ }^{1}$ Department of Civil, Chemical, Environmental and Materials Engineering (DICAM), University of Bologna, \\ Viale del Risorgimento 2, 40136 Bologna, Italy - \\ (ilenia.selvaggi2, mirko.dellapasqua, francesca.franci2, gabriele.bitelli)@unibo.it \\ ${ }^{2}$ Polytechnic Department of Engineering and Architecture (DPIA), University of Udine, \\ Via delle Scienze 206, 33100 Udine, Italy \\ anna.spangher@gmail.com,domenico.visintini@uniud.it
}

Commission II, WG II/8

KEY WORDS: three-dimensional modelling, three-dimensional reconstruction, data comparison, accuracy, Cultural Heritage, FEM

\begin{abstract}
Terrestrial remote sensing techniques, including both Terrestrial Laser Scanning (TLS) and Close-Range Photogrammetry (CRP), have been recently used in multiple applications and projects with particular reference to the documentation/inspection of a wide variety of Cultural Heritage structures.

The high density of TLS point cloud data allows to perform structure survey in an unprecedented level of detail, providing a direct solution for the digital three-dimensional modelling, the site restoration and the analysis of the structural conditions. Textural information provided by CRP can be used for the photorealistic representation of the surveyed structure. With respect to many studies, the combination of TLS and CRP techniques produces the best results for Cultural Heritage documentation purposes. Moreover, TLS and CRP point cloud data have been proved to be useful in the field of deformation analysis and structural health monitoring. They can be the input data for the Finite Element Method (FEM), providing some prior knowledge concerning the material and the boundary conditions such as constraints and loading.

The paper investigates the capabilities and advantages of TLS and CRP data integration for the three-dimensional modelling compared to a simplified geometric reconstruction. This work presents some results concerning the Baptistery of Aquileia in Italy, characterized by an octagonal plan and walls composed by masonry stones with good texture.
\end{abstract}

\section{INTRODUCTION}

As known, a 3D model of a structure requires the acquisition of geometric data, which can be gather with traditional measuring tools (e.g. measuring tapes) or advanced instruments and techniques such as photogrammetry and laser scanning.

Terrestrial Laser Scanning (TLS) and Close-Range Photogrammetry (CRP) have been recently employed in multiple applications. Dense and accurate point cloud data, deriving from TLS and new techniques of CRP, allow to have a very detailed and complete description of the object. In fact, surveying projects very often combine different acquisition methods, and every technique, e.g. TLS and CRP presents obviously some limitations, but also very complementary assets (Grussenmeyer et al., 2008; Gonizzi Barsanti et a., 2012; Pieraccini et al., 2014; Chiabrando et al., 2016). Nevertheless, this type of dataset cannot be used only for descriptive modelling, but can support analyses and studies for different areas of applications (e.g. Barazzetti et al., 2015; Martinez et al., 2015).

Concerning the Cultural Heritage field, the documentation and conservation of ancient buildings is frequently a critical point in the Italian context. In recent years, the digitisation of information offers new methods and different approaches for surveying and monitoring projects with photogrammetry and laser scanning technologies (Bitelli et al., 2017). Three-dimensional visualisation and proper documentation of cultural objects helps to preserve the history and memories of historic buildings, archaeological sites and cultural landscapes.

Several works have demonstrated how Cultural Heritage can greatly benefit from three-dimensional modelling applied to object or historical site analysis, documentation, preservation and restoration (Remondino, 2011; Guarnieri et al., 2017; Murtiyoso and Grussenmeyer, 2017).
Focused on historical buildings, masonry are used in the vast majority of existing monuments, and cracked elements, rotations and non-verticality of the walls (due, for example, to excessive displacement loadings or addition of parts of the building etc...) are a common problem that reduces the service life of these structures (Grimm, 1988). The structural behaviour is highly dependent from the structural geometry. This is the reason why four conditions are required to carry out proper analysis (Guimarães et al., 2014):

- Having a complete and accurate geometric characterization of the structure;

- Knowing the materials mechanical properties;

- Characterizing all the loads acting in the structure;

- Providing numerical models that correctly simulate the characteristic behaviour of the structure.

From irregular geometries, inhomogeneous materials, overlays and additions of elements through the centuries, several configurations and structural behaviour of the building have to be analysed. In this framework, the use of the models derived from geomatic techniques for the structural analysis poses new challenges in the three-dimensional modelling. The result of a full three-dimensional survey is a dense point cloud dataset, deriving from Terrestrial Laser Scanner (TLS), or from digital photogrammetric techniques or, as in the presented case, from an integrated survey, that is the combination of both the approaches. The choice of the proper technique, the post-processing of the data and the combined use of multidisciplinary techniques (Aicardi et al., 2016) depends on the context and other parameters to consider. Starting from a dense and accurate point cloud, all the elements concerning the structure are taken into account, avoiding the loss of elements or important details (Castellazzi et al., 2015). In fact, existing traditional drawings (plans, sections etc.) and documents are very important but in general not 
sufficient, because this information have to be integrated with updated and detailed data.

This paper aims to perform a comparison between the described methodologies, comparing two three-dimensional models; a geometrical model generated starting from traditional tools and historic documentations, and a numerical polygonal model derived from point cloud dataset. As case of study, the Baptistery of Aquileia, in Italy, will be analysed. The comparisons and considerations on these two models highlight the capabilities and the limits of the approaches, in terms of accuracy and potentiality for supporting different further analyses.

\section{CASE STUDY}

The Baptistery is a part of Basilica of Aquileia (Italy) that dates back to the fourth century. The actual configuration is the result of transformations and different reconstructions during the centuries (Bratož, 2007; Brandt, 2007). Along with the Church (called "Church of Pagans"), the Bell Tower composes the structure of the Basilica. The Baptistery is characterized by a square plan outside with a dimension of about $15 \mathrm{~m}$, and by an octagonal plan inside with a dimension of each side of about 6,5 $\mathrm{m}$. The building reaches a height of almost $11 \mathrm{~m}$ and the walls are composed by masonry stones with good texture. The original roof is missing and replaced by steel beams and coverage curtains.

The reasons for choosing this Baptistery as a case study are manifold. First, with its characteristics shape, it is suitable for geometric comparisons and analyses. Secondly, it has undergone various changes and reconstructions, and the overlap between different materials in different periods is an interesting topic.

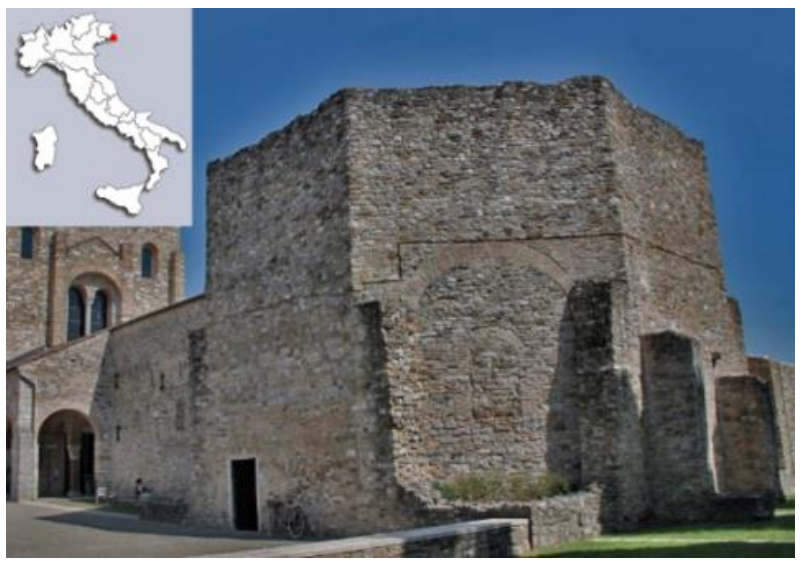

Figure 1. A perspective view of the Baptistery of Aquileia

\section{MATERIALS AND METHODS}

\subsection{Data collection and processing}

In order to obtain a complete description of the object, its surfaces, the thickness and the inclination of the walls, different instruments have been involved for surveying both the interior and the exterior parts.

The measurements started with a TLS survey, planning previously all the scan positions outside and inside Figure 4in order to optimize the acquisition times (Figure 2Figure 3 Figure 4). The survey of the external part was performed using a Riegl Z-390i laser scanner, whereas for the internal structure a Riegl VZ-400 laser scanner was used.

For the registration of the scans, 15 cylindrical $(\phi 10 \mathrm{~cm})$ reflective targets and 55 disk targets $(\phi 5 \mathrm{~cm})$ have been placed over the external parts of the structure. The coordinate values ( $\mathrm{x}$, $\mathrm{y}, \mathrm{z}$ ) for each target have been gained by means of a topographical survey performed using a TCRA 1103 EDM Leica total station.
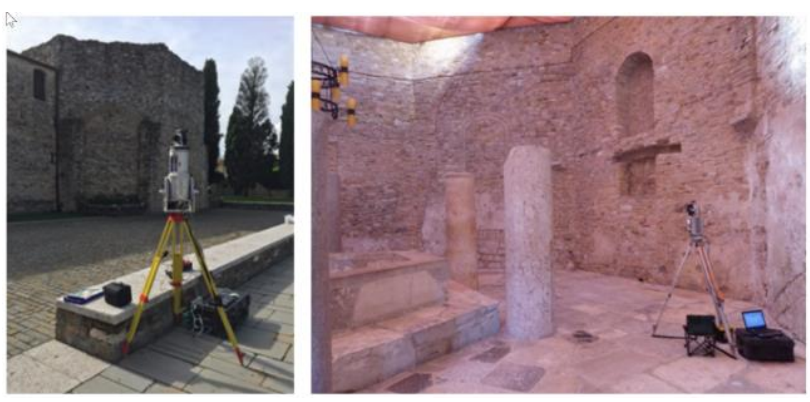

Figure 2. Acquisition of outside (left) and inside (right) using TLS

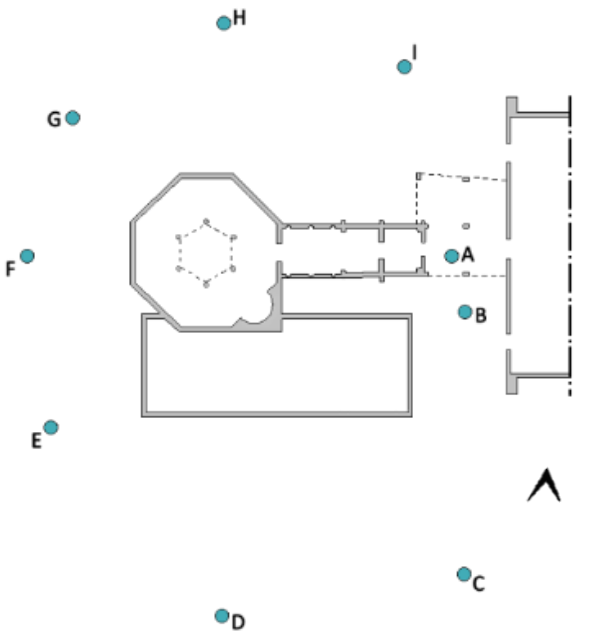

Figure 3. TLS scan positions outside

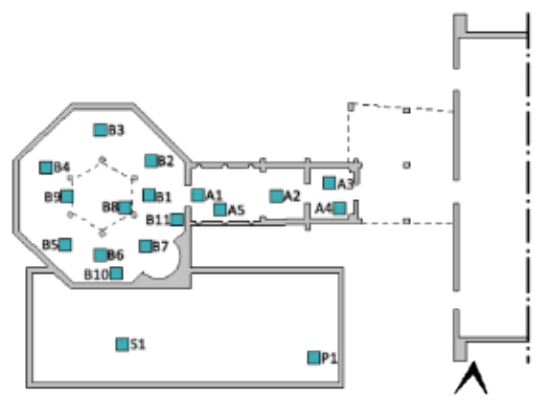

Figure 4. TLS scan positions inside

Due to the position of the scan stations in respect to the building, some missing data affected the high parts of the external walls. The integration of the data coming from a CRP survey allowed to reduce this lack: an extensible tripod was linked to the remote control of the camera and equipped with devices for the real-time visualization and acquisition of the images. With a full frame Canon EOS 6D camera, 77 images have been in this way acquired from three different positions, along the southern side of the Baptistery. An image-based method was then applied to remove the elements (vegetation, sky, buildings etc.) not useful for the three-dimensional model generation.

Finally, using the Multi-View Structure from Motion (SfM) approach implemented in Photoscan Pro package, a point cloud dataset has been obtained. In order to get a good alignment and to scale the point cloud, the markers obtained from the 
topographic survey have been used. A residual error less than 1 pixel has been achieved.

The final point cloud (Figure 5) obtained integrating the TLS and the CRP data consists of more than 40 millions of points (Table 1), of which more than 8 millions belong to the internal and external part of the Baptistery.

Once merged all point cloud datasets, noises, outliers and isolated points were eliminated, and a resampling performed to avoid portions with high difference in the point density. In particular, this operation has been realized for the CRP of the outside and for the TLS of the inside. Considering that the point clouds were characterized by a high level of detail, the resampling operation did not compromise the data quality. Table 1 shows the features of the cleaned datasets.
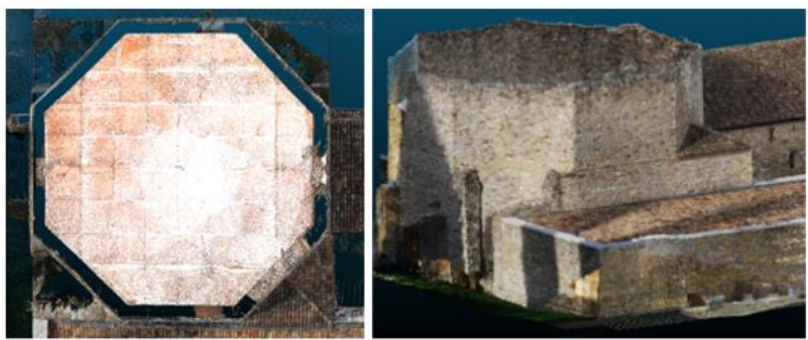

Figure 5. View of the final point cloud from the top (left) and from the southwest side (right) of the Baptistery of Aquileia

\begin{tabular}{|c|c|c|c|}
\hline \multicolumn{2}{|c|}{ POINT CLOUD } & Original Dataset & Cleaned Dataset \\
\hline \multirow[t]{2}{*}{ Outside } & TLS & 3,2 & 2,5 \\
\hline & CRP & 8,2 & 7,2 \\
\hline \multirow[t]{2}{*}{ Inside } & TLS & 24,1 & 22,7 \\
\hline & CRP & 5,1 & 4,6 \\
\hline \multicolumn{2}{|c|}{ TOTAL } & 40,6 & 37 \\
\hline
\end{tabular}

Table 1. Millions of points of the acquired and merged dataset

For the generation of the geometrical three-dimensional model, plans and sections derived from existing documents of the Baptistery have been used. In particular, a ground floor plan dating back to the 1906 (Lanckoronski, 1906) has been considered as reference (Figure 6).

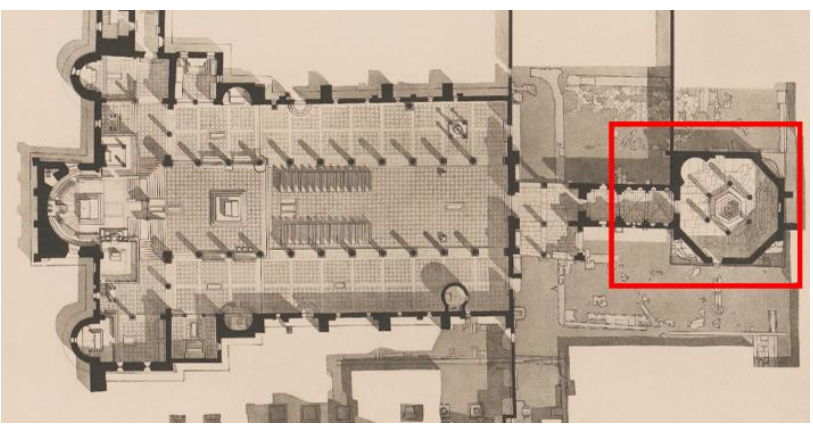

Figure 6. Lanckoronski plan. Red line identifies the Baptistery

\subsection{D modelling}

In order to generate the three-dimensional model, the point cloud of the Baptistery has been isolated from the closed buildings, not a subject of this work. Using the software package Geomagic, the original point cloud has been downsampled to a spatial resolution of $2 \mathrm{~cm}$ and a Triangular Irregular Network (TIN) has been generated from the point cloud dataset. Some operations of mesh repair have been necessary to correct topological or geometrical errors deriving from the transformation of the point cloud into the polygonal model (Attene et al., 2013). Further steps have been faced in order to manually reconstruct those parts occluded to the scanning.

Referring to the "historical" model, the Lanckoronski plan has been scaled according to the actual sizes of the Baptistery. Due to the lack of information, the geometrical model has been obtained considering a constant thickness of the external walls. Furthermore, the value of the height was set equal to the current one. This historical model has been generated by means of the central symmetry using Rhinoceros software.

Figure 7 shows the output of the 3D modelling: the current model, composed by 3.3 million of triangles, and the historical one overlapped to its data source. It is important to underline how the historical model well represents the typical level of detail usually adopted for the structural analysis.

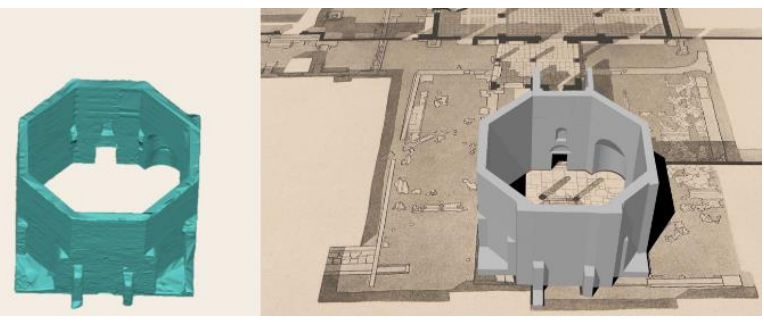

Figure 7. The current numerical model obtained by geomatic surveys (left) and the historical model (right)

\subsection{Geometrical comparisons}

The comparison between the three-dimensional models has been performed in order to highlight the discrepancies resulting from the two approaches. Before the comparison, all unnecessary parts, e.g. modern glass, coverage curtains, the baptismal font with the internal columns, have been deleted.

Firstly, a two-dimensional comparison has been carried out considering "vertical" and "horizontal" analyses.

The "vertical" analysis aims to detect the divergences of the masonry in correspondence of three different vertical portions for each model. The "horizontal" one aims to detect the divergences of the masonry between the two models at the same height.

The two-dimensional comparison has been performed using an image processing approach implemented using eCognition Developer software. In particular, an object-based classification (Franci et al., 2014) has been applied to identify the masonry differences above mentioned. For these purposes, three horizontal sections have been realized at three different heights for each model: $0.5 \mathrm{~m}, 5.5 \mathrm{~m}$ and $10.0 \mathrm{~m}$ (Figure 8). In order to analyse the changes of the masonry, the sections have been transformed into binary images, where white pixels represent empty spaces and black pixels (values equal to zero) indicate filled areas (Figure 9).

The organizational hierarchy in eCognition Developer software enables the image analysis process to be fully automated. The object-based approach has been applied developing a specific ruleset aimed at the segmentation of the sections and their comparison (Bitelli et al., 2004). The goal of the segmentation step was the generation of the image objects i.e. groups of contiguous pixels characterized by the same digital number. Image objects representing the masonry and the background empty space have been generated for each section (Figure 10). Comparing these different group of pixels for pairs of sections, masonry presence in the upper section and not in the lower one, and vice versa, has been evaluated, along with situation of no change. 
In order to take into account the differences also in terms of volume, the two models have been overlaid using CloudCompare software.

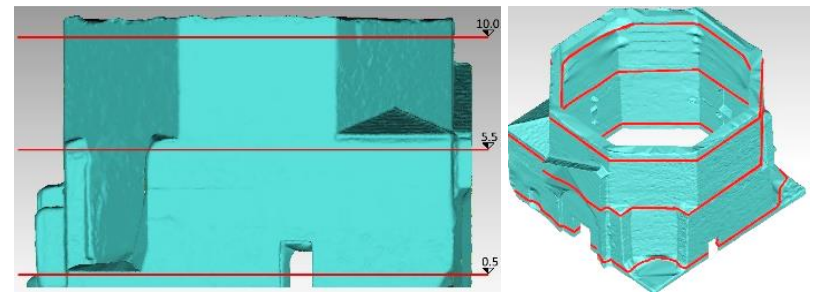

Figure 8 . The polygonal model of the baptistery, with the overlay of the three horizontal sections (red) at three different levels. Frontal view (left) and perspective view (right)
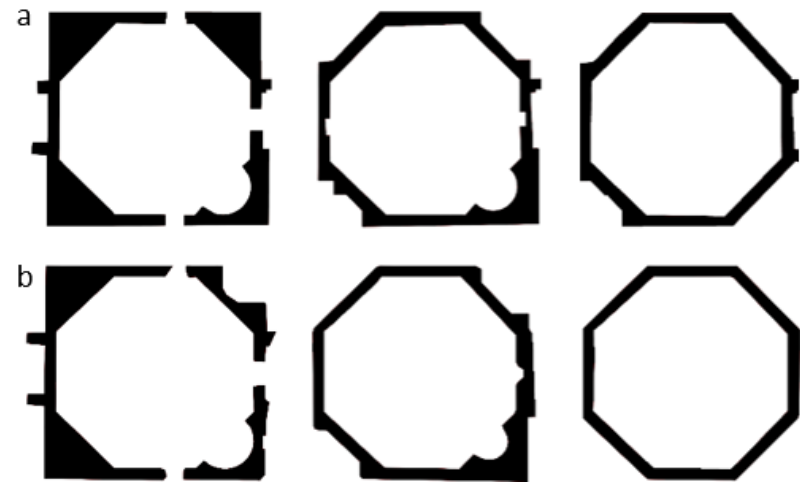

Figure 9. Sections at three different heights, from left: $0.5 \mathrm{~m}, 5.5$ $\mathrm{m}, 10.0 \mathrm{~m}$ of the geometrical model (a) and the numerical model (b)

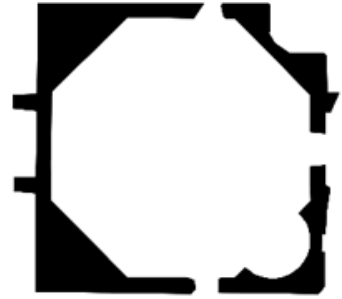

binary image

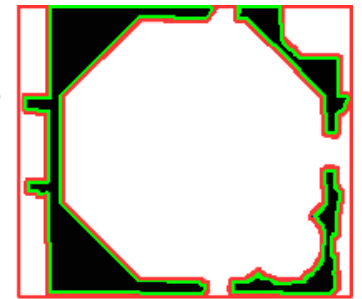

image objects
Figure 10. From the binary image (left) to the image objects (right) by means of the segmentation; the red line represents the background, the green line coincides with the image object representing the masonry

\subsection{FE modelling}

Although this is not a study belonging to the structural field, the transformation from three-dimensional model to the FE model allowed to analyse the differences of using the numerical model rather than the geometrical one, in terms of geometrical characteristics and results derived from the structural analysis. Firstly, the three-dimensional models have been converted into models suitable for structural engineering software, following the Serantoni et al. (2017) approach. The outputs are two voxel models (Truong-Hong \& Laefer, 2013; Ramiya et al., 2016) where the size of each voxel has been chosen considering the Baptistery geometric properties A size equal to $0.20 \mathrm{~m}$ has been set, which corresponds more or less to three layers of bricks and two layers of mortar.
Within Abaqus software, the material characteristics, boundary conditions and forces acting on the Baptistery have been set up according to the legislative framework (NTC, 2008).

Displacements for the first four mode shape and the deviation, considering the current model as reference, have been used to compare the two models.

\begin{tabular}{|c|c|c|c|c|c|}
\hline $\begin{array}{c}\text { Type of } \\
\text { masonry }\end{array}$ & $\begin{array}{c}\mathrm{f}_{\mathrm{m}} \\
\left(\mathrm{N} / \mathrm{cm}^{2}\right)\end{array}$ & $\begin{array}{c}\tau_{0} \\
\left(\mathrm{~N} / \mathrm{cm}^{2}\right)\end{array}$ & $\begin{array}{c}\mathrm{E} \\
\left(\mathrm{N} / \mathrm{mm}^{2}\right)\end{array}$ & $\begin{array}{c}\mathrm{G} \\
\left(\mathrm{N} / \mathrm{mm}^{2}\right)\end{array}$ & $\begin{array}{c}\mathrm{W} \\
\left(\mathrm{kN} / \mathrm{m}^{3}\right)\end{array}$ \\
\hline $\begin{array}{c}\text { masonry stones } \\
\text { good texture }\end{array}$ & 192,6 & 4,15 & 1740 & 580 & 21 \\
\hline
\end{tabular}

Table 2. Reference values of the mechanical parameters, considering the confidence factor equal to 1,35 and the level of knowledge equal to $1 ; \mathrm{f}_{\mathrm{m}}$ is the average compressive resistance of masonry, $\tau_{0}$ is the average shear strength of masonry, $E$ is the average value of the modulus of normal elasticity, $G$ is the average value of the modulus of shear elasticity, $w$ is the average weight of the masonry

\section{RESULTS FROM MODELS COMPARISON}

With reference to the previous description, Figure 11 shows the "vertical" analysis for each pair of sections of each model. Red parts highlight the elements that are not present in the upper section (decrease); otherwise, green areas show the increase of the masonry compared to the lower sections. No changes are represented by grey colour concerning the masonry, and by white areas in terms of empty spaces.

All the results indicated that the real condition of the walls is not constant; in fact, some red parts have been detected only inside the octagonal perimeter of the current model. Red and green areas in correspondence of the outside demonstrate non-orthogonal walls (Figure 11a). On the other hand, for the historical model the 2D comparison shows how the walls are characterized by a symmetrical geometry (Figure 11b).

The "horizontal" procedure indicates some macro differences. In the northeast part of the Baptistery, some green parts highlighted the presence of a step that in the geometrical model was reconstructed as a perfectly boxed solid while its real shape is not homogeneous. The three comparisons indicated a variable thickness of the walls; moreover, a slight rotation has been detected at $10.0 \mathrm{~m}$ height. Relevant differences were also identified in the corners, reconstructed with a perfect geometry in the historical model (Figure 12). Some parts reconstructed through the drawing of Lanckoronski do not exist anymore, and this justifies these discrepancies.
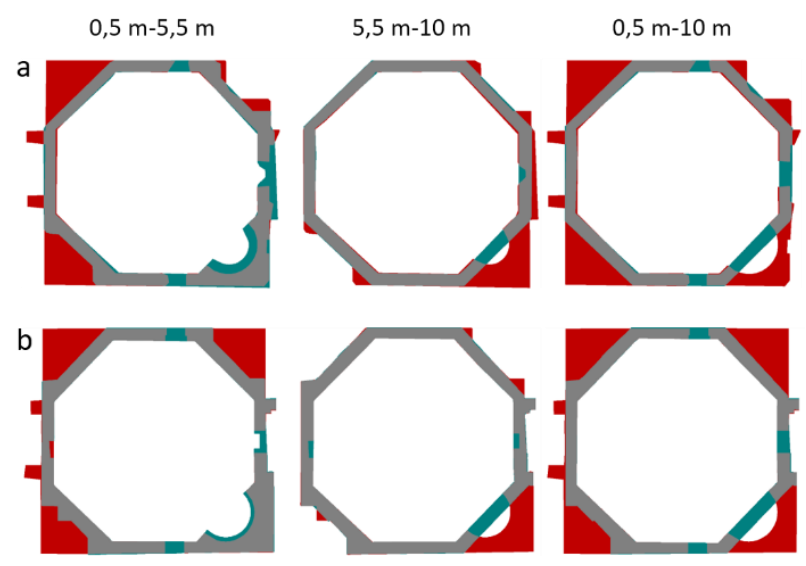

decrease increase

$\square$ no change $\square$ no change - masonry

Figure 11. "Vertical" comparisons for each model: (a) the current model and (b) the historical model 


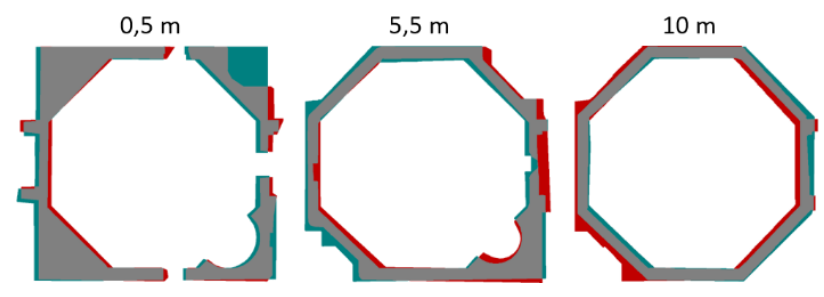

Figure 12. "Horizontal" comparisons between the two models

The 3D comparison performed overlapping the models, confirmed the considerations of the $2 \mathrm{D}$ analysis. Significant differences have been identified in the corners, in the apse and in its vaults (southeast side); in some zones, the discrepancies reached almost $0.9 \mathrm{~m}$ as indicated by the red colour (Figure 13). The different geometry of the apse and its vault is definitely showed by the cross sections in Figure 14: black area is the section of the numerical model, blue part is the section of the geometrical one. The cross sections also confirmed that the perimeter walls are slight inclined outwards of about $0.25 \mathrm{~m}$.
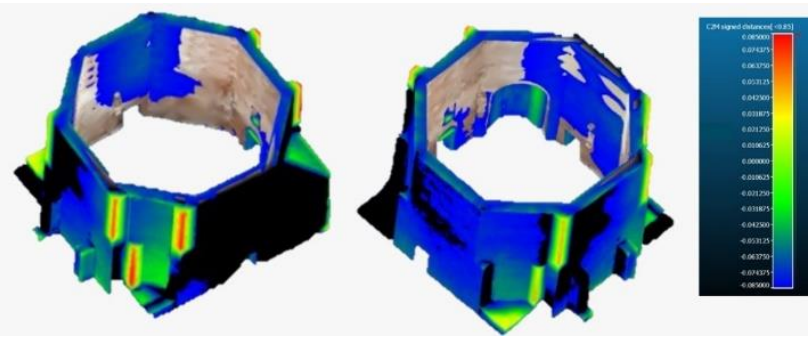

Figure 13. Results of the comparison between three-dimensional models: southwest view (left) and northeast view (right)

\begin{tabular}{|c|c|c|c|c|}
\hline Min. dist. & Max. dist & Avg. dist & Sigma & Max.error \\
\hline 0 & 0,091 & 0,103 & 0,277 & 0,085 \\
\hline
\end{tabular}

Table 3. Statistical values $(\mathrm{m})$ of the overlap between the models
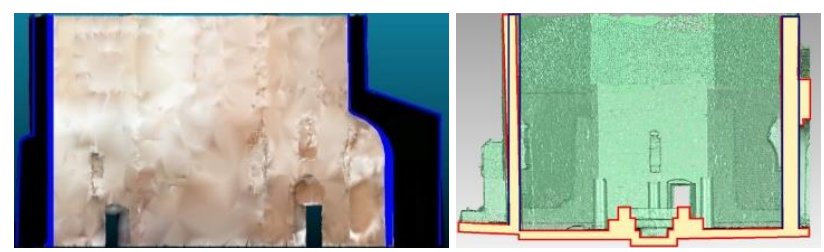

Figure 14. Cross sections

\subsection{FE analysis}

Information about the geometric characteristics of voxel models are reported in the Table 4 . The resulting discrepancies in terms of volume and mass confirmed that the geometrical model is not able to perfectly reproduce the walls in their height and thickness. As already evident in the previous 2D comparison, some elements of the historical plan, not present anymore, influenced these parameters.

Several tests have been performed with different approaches in Selvaggi (2017), and one of these is reported in this work.

The structural analysis results for the two models are shown in Figure 15 and Figure 16; the static behaviour of the Baptistery and the first bending mode along $\mathrm{x}$ direction are respectively reported.

The maximum stress (red voxels in Figure 15) involves almost the same portions of the upper part in both the models; but in the geometrical model, it is possible to observe another high stress zone in the North wall. Moreover, the maximum displacement

value is higher in the geometrical model. The current model is characterized by a lower mass than the historical one; therefore, different bending modes resulted, as shown in Table 5. For the first bending mode, the obtained deviation values underlined greater differences in terms of displacement along $\mathrm{x}$ axis (Figure 16).

\begin{tabular}{|l|c|c|c|}
\hline Model & $\begin{array}{c}\text { Volume } \\
\left(\mathrm{m}^{3}\right)\end{array}$ & $\begin{array}{c}\text { Mass } \\
\text { (tons) }\end{array}$ & $\begin{array}{c}\text { Voxel } \\
(\mathrm{n})\end{array}$ \\
\hline current/numerical & 606,01 & 1201,25 & 66018 \\
\hline historical/geometrical & 717,20 & 1506,13 & 45901 \\
\hline
\end{tabular}

Table 4. The geometric characteristics of two voxel models
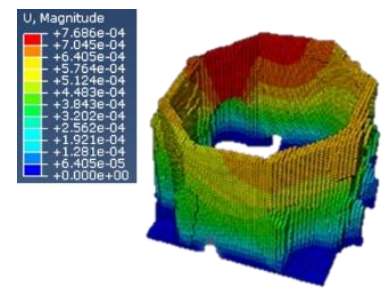

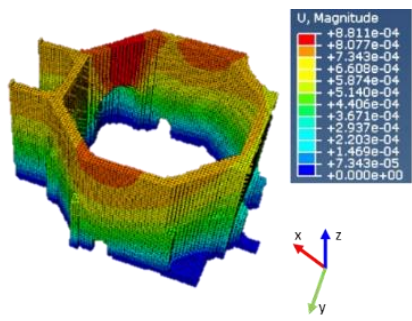

Figure 15. Static analysis of the current/numerical model (left) and the historical/geometrical model (right)
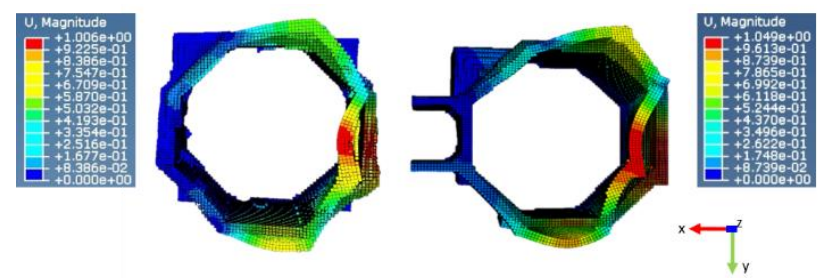

Figure 16. First bending mode along $\mathrm{x}$ direction with the overlap of deformed and undeformed shape. Current model (left) and geometrical model (right)

\begin{tabular}{|c|l|c|c|c|}
\hline $\begin{array}{c}\text { Mode } \\
\text { No. }\end{array}$ & $\begin{array}{c}\text { Mode } \\
\text { description }\end{array}$ & $\begin{array}{c}\text { Max displ. } \\
\text { (current) }\end{array}$ & $\begin{array}{c}\text { Max disp. } \\
\text { (historical) }\end{array}$ & $\begin{array}{c}\text { Deviation } \\
(\%)\end{array}$ \\
\hline 1 & $\begin{array}{l}\text { 1st bending } \\
\text { mode (along x) }\end{array}$ & 1,006 & 1,049 & 4,27 \\
\hline 2 & $\begin{array}{l}\text { 1st bending } \\
\text { mode (along y) }\end{array}$ & 1,063 & 1,086 & 2,16 \\
\hline 3 & axial mode & 1,370 & 1,194 & $-12,84$ \\
\hline 4 & torsional mode & 1,345 & 1,183 & $-12,04$ \\
\hline
\end{tabular}

Table 5. Displacements $(\mathrm{cm})$ of the main mode shapes of the Baptistery

\section{CONCLUSIONS AND FURTHER OUTLOOK}

The analyses performed on the Baptistery of Aquileia highlighted how the three-dimensional models generated starting from the historical data are characterized by standard surfaces without the geometrical details of the current structure. In fact, historical drawings (plans, sections etc.) and documents are fundamental to know the evolution of an ancient building, as the Baptistery, but this information is not sufficient for a detailed and updated representation. As showed in this work, the dense and accurate point cloud data, obtained by means of TLS and CRP techniques, allowed to have a comprehensive description of the Baptistery. This study corroborate that the selection of the documentation and the reconstruction techniques needs to consider the goals of the model and the final analyses. If the aim of the modelling is the reconstruction for architectural and structural purposes, the approach cannot be limited only to a geometrical modelling. The 
mentioned lack can be actually solved by means of TLS and CRP surveys. The performed $2 \mathrm{D}$ and $3 \mathrm{D}$ comparisons suggest the effectiveness of an integrated approach, able to combine different data sources providing a comprehensive geometric set of data in the perspective of Cultural Heritage management and preservation.

The organization of these data and elements allows generating an structured database pertaining to the involved disciplines (preservation, structural analysis, art history, material properties etc.), to be managed through a Historical Building Information Modeling (HBIM). This solution could represent an interesting approach in order to solve some open issues and to guarantee for the future a unique environment where geometrical and textual data can be maintained and updated, from which extract information to support interventions or data to feed different models. Through this approach, complex objects could be subject of different analyses through a common database.

\section{ACKNOWLEDGMENTS}

Authors thank Soprintendenza Belle Arti e Paesaggio del Friuli Venezia Giulia and Società per la Conservazione della Basilica di Aquileia for allowing the surveying activities. Furthermore, authors would like to thank Eugenio Serantoni and Andreas Wieser for the support provided concerning the FE modelling. This work has been partially supported by the GAMHer project: Geomatics Data Acquisition and Management for Landscape and Built Heritage in a European Perspective, PRIN: Progetti di Ricerca di Rilevante Interesse Nazionale - Bando 2015, Prot. 2015HJLS7E.

\section{REFERENCES}

Aicardi, I., Chiabrando, F., Grasso, N., Lingua, A.M., Noardo, F., Spanó, A., 2016. UAV photogrammetry with oblique images: First analysis on data acquisition and processing. Int. Arch. Photogramm. Remote Sens. Spat. Inf. Sci., 835-842. doi: 10.5194/isprsarchives-XLI-B1-835-2016.

Attene, M., Campen, M., Kobbelt, L., 2013. Polygon mesh repairing. ACM Comput. Surv. 45, 1-33. doi: 10.1145/2431211.2431214.

Barazzetti, L., Banfi, F., Brumana, R., Gusmeroli, G., Oreni, D., Previtali, M., Roncoroni, F., Schiantarelli, G., 2015. Bim from laser clouds and finite element analysis: Combining structural analysis and geometric complexity. Int. Arch. Photogramm. Remote Sens. Spat. Inf. Sci. 40, 345-350. doi: 10.5194/isprsarchives-XL-5-W4-345-2015.

Bitelli, G., Balletti, C., Brumana, R., Barazzetti, L., D’Urso, M.G., Rinaudo, F., Tucci, G., 2017. Metric Documentation of Cultural Heritage: Research Directions From the Italian Gamher Project. Int. Arch. Photogramm. Remote Sens. Spat. Inf. Sci. XLII-2/W5, 83-90. doi: 10.5194/isprs-archives-XLII-2-W5-832017

Bitelli, G., Camassi, R., Gusella, L., Mognol, A., 2004. Image change detection on urban area: The earthquake case. Int. Arch. Photogramm. Remote Sens. 35, 692-697.

Brandt, O., 2007. Il battistero "cromaziano", 60-72.

Bratož, R., 2007. La basilica di Aquileia nelle fonti letterarie dal IV al VII secolo 15, 19-66.

Castellazzi, G., D’Altri, A.M., Bitelli, G., Selvaggi, I., Lambertini, A., 2015. From laser scanning to finite element analysis of complex buildings by using a semi-automatic procedure. Sensors 15, 18360-18380. doi: 10.3390/s150818360.

Chiabrando, F., Sammartano, G., Spanò, A., 2016. Historical Buildings Models and their handling via 3D survey:from point clouds to user-oriented HBIM. Int. Arch. Photogramm. Remote Sens. Spat. Inf. Sci. XLI-B5, 633-640. doi:

\subsection{4/isprsarchives-XLI-B5-633-2016}

Franci, F., Lambertini, A., Bitelli, G, 2014. Integration of different geospatial data in urban areas: a case of study, Proc. of SPIE Vol. 9229, 92290P1-92290P9, doi: 10.1117/12.2066614

Gonizzi Barsanti, S., Remondino, F., Visintini, D., 2012. Photogrammetry and laser scanning for archaeological site 3D modeling - some critical issues. Proceedings of the 2nd Workshop on "THE New Technologies for Aquileia" 2012, AACHEN: CEUR Workshop Proceedings, 948, B1-B10.

Grimm, C.T., 1988. Masonry Cracks: A review of the Literature, Masonry: Materials, Design, Costruction and Maintenance, American Society for Testing and Materials, Philadelphia.

Grussenmeyer, P., Landes, T., Voegtle, T., Ringle, K., 2008. Comparison methods of terrestrial laser scanning, photogrammetry and tacheometry data for recording of cultural heritage buildings. Int. Arch. Photogramm. Remote Sens. Spat. Inf. Sci. Vol. XXXVI, 213-218.

Guarnieri, A., Fissore, F., Masiero, A., Vettore, A., 2017. From Tls Survey To 3D Solid Modeling for Documentation of Built Heritage: the Case Study of Porta Savonarola in Padua. Int. Arch. Photogramm. Remote Sens. Spat. Inf. Sci. XLII-2/W5, 303-308. doi: 10.5194/isprs-archives-XLII-2-W5-303-2017

Guimarães, T.C., Sánchez-Aparicio, L.J., Riveiro, B., GonzálezAguilera, D., Ramos, L.F., 2014. The combination of geomatic approaches and operational modal analysis to improve calibration of finite element models : A case of study in Saint Torcato Church (Guimarães, Portugal). Construction and Building Materials 70, 118-129. doi: 10.1016/j.conbuildmat.2014.07.106

Lanckoronski, K.G., 1906. Der Dom von Aquileia, Verlag von Gerlach \& Wiedling, Wien.

Martinez, S., Ortiz, J., Luz, G.M., 2015. Geometric documentation of historical pavements using automated digital photogrammetry and high-density reconstruton algorithms. $J$. Archeol. Sci. 53, 1-11.

Murtiyoso, A., Grussenmeyer, P., 2017. Documentation of heritage buildings using close-range UAV images: dense matching issues, comparison and case studies. Photogramm. Rec. 32, 206-229. doi: 10.1111/phor.12197

NTC 2008, Norme Tecniche per le Costruzioni, D.M. 14/01/08. Pieraccini, M., Dei, D., Betti, M., Bartoli, G., Tucci, G., Guardini, N., 2014. Dynamic identification of historic masonry towers through an expeditious and no-contact approach: Application to the "Torre del Mangia" in Siena (Italy). J. Cult. Herit. 15, 275282. doi: 10.1016/j.culher.2013.07.006

Ramiya, A.M., Nidamanuri, R.R., Ramakrishnan, K., 2016. A supervoxel-based spectro-spatial approach for 3D urban point cloud labelling. Int. J. Remote Sens. 37, 4172-4200. doi: 10.1080/01431161.2016.1211348

Remondino, F., 2011. 3D recording for cultural heritage, In: Remote Sensing for Archaeological Heritage Management, D.Cowley (ed.), Proc. EAC Symposium, pp. 107-116.

Selvaggi, I., 2017. Surveying and three-dimensional modeling for preservation and structural analysis of cultural heritage. $\mathrm{PhD}$ Thesis, University of Bologna, Italy.

Serantoni, E., Selvaggi, I., Wieser, A., 2017. Areal deformation analysis of a visco-plastic structure using point cloud data, in: Lienhart, W. (Hrsg.): Ingenieurvermessung 17, Beiträge Zum 18. Internationalen Ingenieurvermessungskurs.

Truong-Hong, L.; Laefer, D., 2013. Validating Computational Models from Laser Scanning Data for Historic Facades. J. Test. Eval. 41, 481-496. 